\title{
Evaluation of the Maternal Perception of the Oral Health of the Inpatient Infant
}

\author{
Ana de Lourdes Sá de Lira', Joyce de Moura Crisóstomo', Sylvana Thereza de Castro Pires Rebelo ${ }^{1}$ \\ 'Universidade Estadual do Piauí - UESPI, School of Dentistry, Department of Clinical Dentistry, Area of Integrated Clinic, Parnaíba, PI, Brazil
}

\begin{abstract}
Aim: To evaluate the mother's perception of the oral health of their inpatient infants in maternity or infirmary units of a public hospital. Methods: Questionnaire applications were scheduled and educational lectures were carried out on how to sanitize the infant's mouth after breastfeeding, even in the absence of primary teeth, emphasizing the importance of breastfeeding. Results: A significant number of mothers reported that they received no guidance regarding the oral health care of their infants. They had never attended lectures by dental practitioners, as well as they did not know that the use of pacifier, baby bottle and digital sucking habit could interfere with their infant's oral heath over time. Conclusions: The majority declared that they had no care with the oral health of their infants. Only five mothers of newborns reported that they performed the oral hygiene of them once a day after the first breastfeeding. The mothers showed lack of knowledge on the diseases which can affect their children during early infancy as they had no information on how to prevent them. They did not know that early caries lesions could affect the infant and that harmful oral habits can predispose to the development of malocclusions.
\end{abstract}

Keywords: Odontopaediatrics. Prevention. Infants.

\section{Introduction}

The parents assume a caretaker role which is crucial for promoting and maintaining the health of their children, and for this reason they should be the primary source of information on oral health. Mothers have more influence on the child because they are more present as a caretaker, and when they are well instructed by healthcare practitioners, can form attitudes and behaviours and transform them into generation of healthy habits ${ }^{1,2}$.

Dental caries is the most prevalent chronic disease in the infancy, being classified even as a "pandemic" condition characterised by a high rate of untreated cavities, thus causing pain, distress and functional restrictions among the children ${ }^{3}$. A poor oral health can increase the risk of caries in infants, since the mother's saliva is the main source

Received for publication: December 15, 2016 Accepted: May 3, 2017

Correspondence to: Ana de Lourdes Sá de Lira Universidade Estadual do Piauí

Faculdade de Odontologia Rua Senador Joaquim Pires 2076 - Ininga Fone (86) 999595004 CEP: $64049-590$ - Teresina-PI-Brasil email: anadelourdess!@hotmail.com of cariogenic bacteria for the infant's oral microbiota. Mothers who have untreated decayed teeth are more risky of transmitting bacteria to their children ${ }^{4,5}$.

In order to reduce the risk of dental caries and promote the children's oral health, hygiene measures should be implemented even before the eruption of the first deciduous tooth. The teeth should be cleaned at least twice a day under supervision of the caretaker, who can use a diaper or soft toothbrush to decrease the bacterial colonisation by disorganising dental plaques ${ }^{6-8}$.

Healthy or harmful habits are behavioral patterns which are learnt by the child. The importance of breastfeeding and infant oral hygiene should be taught to the 
parents during medical and dental healthcare services throughout gestation and during routine medical visits?.

Non-nutritive sucking habits can lead to undesirable effects on dental arches. The continuous presence of the thumb or finger inside the oral cavity can exert pressure enough to deform the upper arch, palate or both. If this digital sucking habit persists while the permanent teeth are erupting, then harmful effects on dentofacial development can occur ${ }^{10}$.

The parents should be informed about the benefits to the infant from breastfeeding during the first 6 months of life in terms of normal development of the dentofacial skeleton. The non-nutritive sucking habit should be diagnosed in time so that the development of posterior cross-bite, anterior open-bite and Class II malocclusion can be reduced ${ }^{9}$.

It is believed that the pregnant women during the prenatal and after delivery are not oriented on the preventive measures of caries and malocclusion of infants, although healthcare professionals know that the infant oral health care depends on the parent's awareness.

It is further believed that even in the territories covered by the Family Health Strategy, with or without the participation of the dentist even if the dentist does not participate in the home visit, the Community Health Agents usually fails do it, and does not refer them for healthcare in the Basic Health Unit whenever necessary. It occurs especially in cities of poor states or in rural areas where socioeconomic conditions hamper monthly consultations during prenatal care.

In this context, we sought to know whether the mothers were being instructed on infant oral hygiene, so that guidance programs on the oral health of infant could be improved, in Basic Health Units, where prenatal care is performed. Therefore, the objective of this work was to evaluate the mother's perception of the oral health of their inpatient infants in maternity or infirmary units of a public hospital.

\section{Material and methods}

The researcher obtained a signed informed consent form from the Public Hospital of Parnaíba (Piauí) authorising the development of the study, which was also approved by the human research ethics committee of the State University of Piauí (CEP/UESPI) according to protocol number CAAE 16604613.2.0000.5209. The researchers carried out the study according to an individual schedule of activities as detailed in the project.

Informed consent forms were distributed to the mothers, including those younger 18 years old, explaining the objective of the study. In this way, it was possible to obtain their consent on a free-will basis after they agreed and signed the forms. Only mothers with infants aged up to 18 months old (age limit for infants) in the maternity or infirmary units during the second semester of 2014 participated in the study, totalizing 42 mothers, being 34 residents in the rural area, who were with their infants hospitalized for medical treatment.

We opted to carry out the study in the maternity unit of the Dirceu Arcoverde state hospital, since we believed that these parturients were less instructed by the hospital staff about infant oral health compared to those attended in private hospitals. It should also be emphasised that we already expected that the population attended in this public hospital had low income and low education level, which would contribute to their lack of knowledge on the importance of breastfeeding and keeping healthy habits for the oral health of their infants.

The present research not only respected the determinations of the resolution number 466/12 of the National Health Council, but also guaranteed confidentiality, anonymity and non-use of information in detriment of the individuals, thus reducing the risk to the subjects (the results only contribute to the present study by means of statistical assessment of the data obtained with the questionnaire)

A pilot survey was initially undertaken by one examiner for calibration purposes, and the same questionnaire was applied to five mothers who were with their infants in the infirmary of the same hospital on the first Sunday of the first week of July in 2014. The questionnaire was applied again to the same mothers on the Friday of the same week, prior to the discharge of their infants, thus totalizing 10 questionnaires. No discrepancies in the answers were observed between the questionnaire applications in both periods of time. The visits for questionnaire applications were scheduled in the mornings on Tuesdays and Thursdays of each week during the second semester of 2014

Educational lectures were carried out on how to sanitize the infant's mouth after breastfeeding, even in the absence of primary teeth, emphasizing the importance of breastfeeding, prevention of digital sucking habits or pacifiers. Before the first teeth erupted it was emphasized that oral hygiene should be performed using clean diaper / gauze moistened with filtered or boiled water at the time of body hygiene ${ }^{5,7}$.

For the child who was being breastfed exclusively at the breast, it was advised that mouth cleaning should be restricted to the tongue once a day because breast milk contains immunoglobulins that protect the child's mouth from infections. If the child is using artificial breast-feeding, cleaning should be performed throughout the oral cavity twice a day ${ }^{6,7}$.

This is a cross-sectional, quantitative, qualitative study whose resulting data were analysed by using the PASW statistical package, version 21. Descriptive statistical analyses (measurements of central tendency and dispersion) were also performed, including the Spearman's rank correlation (one-tailed test).

\section{Results}

The study used a convenience sample (non-probabilistic) of 42 mothers with inpatient infants in a public hospital in the city of Parnaiba (Piauí). The subjects had a mean age of 23.04 years old $(\mathrm{SD}=6.01$, range between 17 and 39 years). Table 1 lists the social-economic data of our sample.

With regard to the infant age group, $88.1 \%(\mathrm{n}=37)$ were newborns and five were between 12 and 18 months old. In Table 2 , one can see the mothers' answers on whether they received some guidance on infant oral hygiene. The majority of the mothers interviewed during their stay in the hospital reported that they received no visit of a dentist, corresponding to $90.5 \%$ 
$(\mathrm{n}=38)$ of the subjects. Only one mother reported that she had received such a visit, whereas other three mothers did not answer.

Table 1 - Social-economic data of the mothers participating in the study.

\begin{tabular}{lcc}
\hline VARIABLES & \multicolumn{2}{c}{ FREQUENCY } \\
\hline & $\mathrm{N}$ & $\%$ \\
\hline Education level & 9 & 21.4 \\
Elementary education & 20 & 47.6 \\
Incomplete elementary education & 5 & 11.9 \\
Intermediate education & 4 & 9.5 \\
Incomplete intermediate education & 2 & 4.8 \\
Higher education & 1 & 2.4 \\
Incomplete higher education & 1 & 2.4 \\
Illiterate & & \\
Marital Status & 19 & 45.2 \\
Single & 12 & 28.6 \\
Married & 11 & 26.2 \\
Stable union & & \\
Income & 41 & 97.6 \\
1 to 2 minimum wages & 1 & 2.4 \\
3 to 4 minimum wages & &
\end{tabular}

Source: Direct Research Parnaíba 2015

Table 2 - Questionnaire on the oral health of infants aged between 0 to 18 months old.

\begin{tabular}{lcc}
\hline VARIABLES & \multicolumn{2}{c}{ FREQUENCY } \\
\hline & $\mathrm{N}$ & $\%$ \\
\hline Have you ever received some guidance on & & \\
infant oral hygiene? & 38 & 90.5 \\
No & 4 & 9.5 \\
Yes & & \\
By whom? Where? & 4 & 9.5 \\
Nurse & 1 & 2.4 \\
Basic health unit & 1 & 2.4 \\
Physician & 1 & 2.4 \\
Hospital & 35 & 83.3 \\
No answer & & \\
\hline
\end{tabular}

Source: The respondents could answer more than one choice. Direct Research Parnaíba 2015

The mothers were asked how many times a day they performed the oral hygiene of their infants. The majority $(73.8 \%$; $\mathrm{n}=31$ ), declared that they had no care with the oral health of their infants. Only five mothers of newborns reported that they performed the oral hygiene of them once a day after the first breastfeeding. With regard to the mothers of infants between 12 and 18 months, one did it twice a day, in the morning and after the lunch; three did it three times a day, in the morning, after the lunch and before sleeping; and only one mother reported that she did it more than 3 times a day, always after any meal.

The mothers were also asked on whether they had ever participated in some lecture by a dentist. The majority answered negatively $(81 \% ; n=34)$, whereas only eight reported that they had already participated. Only seven mothers reported that they knew that caries and candidiasis could be the result of poor oral hygiene, whereas $76.2 \%(n=32)$ answered that they did not know which diseases might affect the infant in the absence of such care. Three mothers refused to answer this question. Three of the subjects knew to define the so-called baby bottle tooth decay, but $92.9 \%(\mathrm{n}=39)$ reported having no knowledge about it.

Table 3 lists the data from the question on the best measures to be taken to prevent caries. In the time of the study, it was also asked whether caries lesion could be transmitted from the mother to the infant, with $63.4 \%(\mathrm{n}=27)$ answering negatively while $36.6 \%(n=15)$ believing it was true. However, only one mother reported that this might occur during a very close conversation with the infant. Among the 42 mothers, $76.2 \%$ (n $=32$ ) reported that their infants were breastfed only, whereas four were fed with artificial milk and six fed with both.

In the present study, $92.9 \%(\mathrm{n}=39)$ of the mothers reported they did not know that the use of pacifier, baby bottle and digital sucking habit could interfere with their infant's oral heath over time. All the mothers were unanimous in stating that their infants had the habit of putting the finger into the mouth.

Table 3 - Question on caries lesions.

\begin{tabular}{lcc}
\hline VARIABLES & \multicolumn{2}{c}{ FREQUENCY } \\
\hline & $\mathrm{N}$ & $\%$ \\
\hline Which is the best measure to prevent caries & & \\
from occurring in the future? & 15 & 35.7 \\
Hygiene of the mouth & 7 & 16.7 \\
Food control & 16 & 38.1 \\
Visit to the dentist & 1 & 2.4 \\
Food control and visit to the dentist & 1 & 2.4 \\
Hygiene of mouth and food control & 2 & 4.8 \\
No answer &
\end{tabular}

Source: The respondents could answer more than one choice.

\section{Discussion}

A social-economic questionnaire was used in the present study to determine the profile of the population sample, which can contribute to the development of further contextualised policies so that people's needs can be met according to the characteristics observed in the population studied.

The subjects had a mean age of 23.4 years old, with $47.6 \%$ (n $=20)$ not completing the elementary school, $45.2 \%(\mathrm{n}=19)$ being single, $97.6 \%(\mathrm{n}=41)$ having monthly income of 1 minimum wage, and $88.1 \%(\mathrm{n}=37)$ having newborn infants (Table 1$)$.

In the present study, after performing the Spearman's rank correlation (one-tailed test) between the variables (i.e. education level versus mothers' knowledge on diseases which might affect the infant due to poor oral hygiene), it was possible to observe a significantly positive relationship between both $\left(\mathrm{r}=-0.45^{*} \mathrm{p}<\right.$ $0.01)$. It was observed that the higher the education level of the mother, the greater of knowledge on diseases which might affect the infant as a result of poor oral hygiene.

Campos et al. ${ }^{11}$ (2010), by analysing the social-economic aspect of the mothers, found that the lower the social-economic class, the higher the percentage of lack of knowledge. This finding was also observed in the present study.

The majority of the mothers $(90.5 \%)$ reported that they had never received any information on infant oral health (Table 
2), a finding not corroborated by Guarienti et al12 (2009), who concluded that $83 \%$ of the mothers interviewed reported they had such information, but out of the dental office, hospital or healthcare unit environment.

Also drawing attention was the finding that $73.8 \%$ of the mothers declared that they took no care of the oral health of their infants. In another study, $96 \%$ of the mothers stated that infant oral health is necessary, but $63 \%$ did not know to explain how it should be done ${ }^{13}$.

In a study of pregnants, the future mothers were asked on whether they knew about caries in the early childhood, the so-called baby bottle tooth decay, and $96.25 \%$ of them had no knowledge about it ${ }^{14}$. Such finding was also reported in our study. According to the literature, early dental caries or baby bottle tooth decay should be prevented as this condition progresses rapidly, resulting in destruction of tooth crowns in a short space of time, or even early loss of teeth, which can lead to malocclusion ${ }^{10-14}$.

Guarienti et al. ${ }^{12}$ (2009) conducted a research in which half of the mothers responded that they did not know whether caries could be transmitted from the mother to the child. Similarly, the subjects of our study $(61.9 \%)$ responded they did not know about such a possibility.

Serpa and Freire ${ }^{15}$ (2012) found that $85 \%$ of the mothers interviewed were aware that one of the best ways to prevent caries from occurring in the future would be an adequate oral hygiene. This finding is also corroborated by our study, since only $38.1 \%$ of the mothers know this correlation (Table 3).

By means of questionnaires, Charchut et al. ${ }^{16}$ (2003) and Massoni et al. ${ }^{17}$ (2010) found that prolonged breastfeeding beyond the first two years of life can favour the establishment of non-nutritive sucking habits, such as the use of pacifiers. The interviewees considered the prolonged use of pacifiers harmful to the child. However, a few ones had knowledge about the age limit for stopping this habit in order to avoid compromising the dentofacial development, since self-correction occurs up the age of 3 years approximately.

Differently from our study, $92.9 \%$ of the mothers did not believe that the use of pacifier, baby bottle and digital sucking habit could interfere with the infant oral health over time.

During the study, the mothers were instructed by the researchers about the need to perform the infant oral hygiene, including different ways of doing it, as well as the harms affecting the infants as a result of non-nutritive sucking habits. Also, educational folders were handed out to the mothers.

It is necessary to provide more information for mothers, especially those not attending public hospitals, so that they can take care of the oral health of their infants accordingly, regardless of being in healthcare units, hospitals or lectures by dentists or other healthcare practitioners in the community.

On conclusion, the majority declared that they had no care with the oral health of their infants. Only five mothers of newborns reported that they performed the oral hygiene of them once a day after the first breastfeeding. Those participating in the study showed lack of knowledge on the diseases which can affect their children in early infancy, since they received no information on how to prevent them. Particularly, the mothers did not know that early tooth decay can affect the infant and that harmful oral habits can predispose to the development of malocclusion.

\section{References}

1. Sisson $\mathrm{KL}$. Theoretical explanations for social inequalities in oral health. Community Dent Oral Epidemiol. 2001 Apr;35(2):81-8.

2. Wandera M. Factors associated with caregivers' perception of children's health and oral health status: a study of 6-to 36-month-olds in Uganda. Int J Paediatr Dent. 2009 Jul;19(4):251-62. doi: 10.1111/j.1365263X.2009.00969.x.

3. Sufiaa S, Chaudhry S, Izhar F, Syed A, Mirza BAQ, Khan AA. Dental caries experience in preschool children- Is it related to a child's place of residence and family income? Oral Health Prev Dent. 2011;9(4):375-9.

4. Berkowitz RJ. Acquisition and transmission of Mutans Streptococci. J Calif Dent Assoc. 2003 Feb;31(2):135-8.

5. Milgrom P, Huebner CE, Mancl L, Garson G, Grembowski D. Counseling on early childhood caries transmission by dentist. 2013 Spring;73(2):151-7. doi: 10.1111/j.1752-7325.2012.00356.x.

6. Riter D, Maier R, Grossman DC. Delivering Preventive Oral Health Services In Pediatric Primary Care: A Case Study. Health Aff (Millwood). 2008 Nov-Dec;27(6):1728-32. doi: 10.1377/hlthaff.27.6.1728.

7. Guideline on Infant Oral Health Care. American Academy of Pediatric Dentistry. 2009;31:95-9.

8. Sutthavong S, Taebanpakul S, Kuruchitkosol C, Ayudhya TI, Chantveerawong $T$, Fuangroong $S$ et al. Oral health status, dental caries risk factors of the children of public kindergarten and schools in Phranakornsriayudhya, Thailand. J Med Assoc Thai. 2010 Nov;93 Suppl 6:S71-8

9. Jyoti S, Pavanalakshmi GP. Nutritive and Non-Nutritive Sucking Habits - Effect on the Developing Oro-Facial Complex: A Review. Dentistry. 2014:4:203-6.

10. Franco Varas V, Gorritxo Gil B. [Pacifier sucking habit and associated dental changes. Importance of early diagnosis]. An Pediatr (Barc). 2012 Dec;77(6):374-80. doi: 10.1016/j.anpedi.2012.02.020. Epub 2012 May 18. Spanish.

11. Campos L, Bottan ER, Birolo JB, Silveira EG, Schmitt BHE. [Knowledge of mothers from different social classes regarding oral health in the city of Cocal do Sul (SC)]. Rev Sul-Bras Odontol. 2010 Oct-Dec;7(4):287-95. Portuguese.

12. Guarienti CA, Barreto VC, Figueiredo MC. [Parents' and caregivers' knowledge of oral health in the early childhood]. Pesq Bras Odontoped Clin Integr. 2009;9(3):321-5. Portuguese.

13. Praetzel JR, Ferreira FV, Lenzi TL, Melo GP, Alves LS. [Maternal perceptions of dental, speech and hearing care during pregnancy]. RGO. $2010 \mathrm{Apr}$ Jun;58(2):155-60. Portuguese.

14. Marín C, Pereira CC, Koneskl K, Andrades KMR, Miguel LCM, Ávila LFC. Evaluation of pregnant adolescent women's knowledge about their baby's oral health. Arq Odontol. 2013;49(3):133-9. Portuguese

15. Serpa EM, Freire PLL. [Perception of pregnants from in João Pessoa-PB on the oral health of its babies]. Odontol Clin-Clent. 2012;11:121-5. Portuguese.

16. Charchut SW, Alfred EN, Needleman HL. The effects of infant feeding on the oclusion of the primary dentition. J Dent Child (Chic). 2003;70(3):197-203.

17. Massoni ACLT, Paulo SF, Forte FDS, Freitas CHSM, Sampaio FC [Children's oral health: knowledge and interest of parents/caregivers]. Pesq Bras Odontop Clin Integr. 2010;10:257-64. Portuguese. 